\title{
FOGÃO FOGUETE COMO PROPOSTA DE PRÁTICA EXPERIMENTAL PARA O ENSINO DE FÍSICA
}

\section{ARTIGO ORIGINAL}

SILVA, Rafael Leal da ${ }^{1}$

SILVA, Rafael Leal da. Fogão foguete como proposta de prática experimental para o ensino de Física. Revista Científica Multidisciplinar Núcleo do Conhecimento. Ano 05, Ed. 07, Vol. 02, pp. 28-42. Julho de 2020. ISSN: 2448-0959, Link de acesso: https://www.nucleodoconhecimento.com.br/fisica/fogao-foguete

\section{RESUMO}

As práticas experimentais possibilitam aos discentes um ambiente em que a aprendizagem ocorre de maneira interativa, dando assim, oportunidade para criarem hipóteses e testá-las em um ambiente onde o professor é o mediador no processo de ensino-aprendizagem. Devido à pouca oferta de laboratórios equipados em algumas localidades, faz-se necessário recorrer a alternativas, em especial, àquelas com propostas de baixo custo e sustentáveis. Este artigo apresenta resultados qualitativos assim como uma proposta para o ensino de tópicos de termodinâmica utilizando como objeto didático o fogão foguete, o qual tem sido estudado em todo o mundo por ser menos poluente e mais eficiente energeticamente do que os fogões que utilizam biomassas disponíveis para regiões do mundo economicamente vulneráveis. Por ser um tema comum para a maioria dos alunos envolvidos, na atividade proposta neste artigo o fogão foguete além de facilitar o ensino de conceitos de Física, possibilitou uma discussão sobre sustentabilidade no contexto da aula experimental. A prática experimental foi feita dentro da proposta do laboratório divergente, pois nesse tipo de ambiente, o aluno tem mais liberdade para ser o principal promotor de seu processo de aprendizagem, além de possibilitar uma participação interativa entre grupos. Uma

\footnotetext{
${ }^{1}$ Doutor em Física da matéria condensada, Mestre em Física da matéria condensada, especialista em metodologia do ensino de Física e licenciatura em Física.
} 
proposta quantitativa com base nos estudos de Okonkwo et al (2017) também é apresentada neste artigo para uma turma mais avançada de Física. De um modo geral, após a realização e durante o experimento, foi notório a empolgação dos alunos com o modo em que estavam aprendendo a Física, por ir além da metodologia rígida tradicional das aulas teóricas.

Palavras-chave: Fogão foguete, ensino de Física, práticas experimentais, laboratório divergente.

\section{INTRODUÇÃO}

O ensino de Física enfrenta grandes desafios quanto à transposição didática. O modo tradicional de se ensinar vem sendo criticado por pesquisadores em ensino como não sendo eficiente para superar a crise educacional desta disciplina no Brasil. Entre as propostas para a solução dos problemas, o ensino que utiliza como ferramenta as práticas experimentais tem sido apontado como de suma importância, já que a Física tem caráter experimental que não pode ser dissociado da disciplina (PINHO-ALVES, 2002; FARIA e CARNEIRO, 2020; FORÇA et al, 2011; KANBACH et al, 2005; ANDRADE, 2009).

Pinho-Alves (2000) chama a atenção para o uso do laboratório didático enquanto processo de ensino. Nesse ponto de vista, tem o poder de mediar e alertar para que não se incorra no antigo paradigma que o via apenas como um método experimental. Logo, a atuação no espaço escolar junto aos discentes deve-se levar em conta a transposição didática que torne mais acessível o processo de transformação do saber a ensinar ao saber ensinado (PINHO-ALVES, 2000). Além disso, segundo ele, a transposição didática irá ocorrer por intermédio do construtivismo no modo de encarar a produção da Ciência durante o processo ensino-aprendizagem.

Para aplicação de projetos de práticas experimentais como partícipe da transposição didática, se faz necessário o conhecimento da realidade do ambiente escolar, assim como o contexto sociocultural da instituição, o projeto político pedagógico e a legislação educacional. Todos esses fatores influenciam no uso de laboratórios 
didáticos nas escolas. Além dos fatores já citados, há o processo de formação de professores atrelado à resistência por parte dos gestores escolares e pedagógicos às mudanças no modo tradicional de ensino. Tratando dessa influência das pessoas envolvidas no ambiente escolar, Pinheiro comenta sobre a dificuldade em incluir o laboratório didático no ensino:

Para ele concorrem mais acentuadamente os grupos da noosfera vinculados à comunidade escolar, como a direção de escolas públicas, proprietários de estabelecimentos de ensino, os supervisores e orientadores educacionais, a comunidade dos pais e os professores. São inúmeros os aspectos que concorrem para a definição do saber a ser ensinado, mas podemos identificar que ele é definido pela possibilidade de um controle social e legal da aprendizagem. (PINHEIRO, 1996)

$\mathrm{Na}$ perspectiva construtivista, as atividades experimentais simplificam o processo didático, onde o professor é o manipulador desta ferramenta. Deste modo, na transposição construtivista, o experimento não é mais um objetivo a ensinar, mas sim um elemento agregador no processo de aquisição do conhecimento. Logo, com esse objetivo, a sua aplicação deverá se caracterizar pela versatilidade, para que assim assuma um caráter mediador (PINHO-ALVES, 2002).

Ao implementar o uso de laboratório e toda dinâmica envolvida, se faz necessário a escolha de qual tipo de laboratório utilizar. Em contraste com o modelo de laboratório tradicional, que sua ênfase é a verificação ou a comprovação de lei e ainda a exploração de conceitos à exaustão, o laboratório divergente tem como principal objetivo, possibilitar ao estudante o poder de decidir quanto ao esquema e ao procedimento experimental a ser adotado (PINHO-ALVES, 2002).

Com relação à aplicação do laboratório divergente, existe duas etapas. A primeira etapa, denominada "exercício", ocorre no momento em que os alunos realizam atividades e se adaptam aos equipamentos e instrumentos de medidas e técnicas experimentais, assim como a teoria apresentada. Nesta etapa, a finalidade principal é o treinamento dos estudantes. Já na segunda etapa, conhecida como "experimentação", o aluno escolherá qual atividade realizará, assim como seus objetivos, hipóteses e quais medidas executarão. Após o planejamento, os alunos 
devem discutir com o professor, para assim ponderarem sobre eventuais correções de suas conclusões, além da viabilidade dos materiais a serem utilizados dentro do prazo previsto da prática experimental (PINHO ALVES, 2000; BORGES, 2002). Por sua versatilidade e possibilidades em modificações fora dos padrões rígidos dos laboratórios tradicionais, o laboratório divergente foi adotado como ferramenta neste trabalho.

Ainda no contexto das práticas experimentais, Pearce (2007) defende o uso de projetos tecnológicos voltados à sustentabilidade, além de propor materiais que possam ser usados em locais de difícil acesso a laboratórios de ensino por conta de condições sociais em vários países subdesenvolvidos. No tocante ao ensino da termodinâmica, Pearce indica experimentos com resfriamento evaporativo, fogões/fornos, fogão solar, desidratador de comida e outros dispositivos de uso solar.

No Brasil, a matriz energética de biomassa corresponde a um quinto de toda a energia consumida no país (MAIA e GOMES, 2009). Isso abre espaço para uma discussão ampla tanto no sentido da Física puramente dita, quanto em temas mais gerais como aquecimento global, efeito estufa, desmatamento, conservação ambiental, emissão de gases tóxicos e perigo para a saúde. Tais temas dificilmente seriam abordados em uma aula tradicional de Física ao se ensinar os tópicos de termodinâmica (MAZORRA et al, 2019; GOLDEMBERG e LUCON, 2007; SILVA, 2019; SANTOS, 2017; CARVALHO, 2014).

Este trabalho apresenta uma proposta pedagógica de prática experimental utilizando como objeto de estudo o fogão foguete por possibilitar uma abordagem multidisciplinar dos temas: energias renováveis, sustentabilidade, experimentos com materiais de baixo custo e ensino da termodinâmica de uma maneira mais próxima ao dia a dia dos alunos.

\section{EXPERIMENTAÇÃO NO ENSINO DE FÍSICA}

Tanto os organizadores de planos de estudos quanto os professores, ao utilizarem trabalhos práticos, encontram dificuldades, como aponta Hodson (1994). Geralmente, 
essas dificuldades ocorrem devido às barreiras desnecessárias que dificultam a aprendizagem com o excesso de informações. Assim, Hodson argumenta que pode ser adotada duas estratégias. A primeira: adotar um enfoque de receita onde 0 experimento tem um objetivo simples e um roteiro passo a passo. A segunda: um comportamento aleatório que faça o aluno parecer ocupado. Aqui, há a necessidade de cuidado ao propor uma prática experimental, eliminando os passos muito elaborados e evitar dar muita atenção às medidas de uma única variável (HODSON, 1994).

Para ele, o ensino de Ciência possui três principais aspectos relevantes convergentes:

1. Aprendizagem de ciência adquirindo e desenvolvendo conhecimento teórico e conceituais;

2. Aprendizagem sobre a natureza da ciência desenvolvendo um entendimento da natureza e os métodos das ciências, sendo conscientes das interações complexas entre conhecimento e desenvolvimento social;

3. Práticas de ciência, desenvolvendo os conhecimentos técnicos sobre a investigação científica e a resolução de problemas. (HODSON, 1994)

Do mesmo modo que a experimentação é fundamental para o fazer científico, ela deve ser fundamental no ensino de Ciência. Segundo afirma Hodson (1994), os organizadores e professores ainda não fazem distinção entre prática experimental e o processo ensino-aprendizagem. Ele ainda declara que muitos comentem o erro de entender a prática experimental somente como aquele tipo de trabalho feito em bancada de laboratório.

Apesar de se mostrar uma ferramenta com eficácia comprovada no ensino, a experimentação sofre críticas no sentido de sua aplicação, visto que há práticas demasiadas complexas que poderiam ser mais prejudiciais ao ensino do que eficazes. Para Séré (2002), existe diferentes formas de incluir as práticas experimentais no ensino, tendo diferentes resultados: 
1. Compreender a teoria, os conceitos, os modelos, as leis, os raciocínios específicos, que muitas vezes diferem notavelmente do raciocínio corrente;

2. Aprender toda a teoria;

3. Realizar experiências mostrando um certo número de realidades, fatos e instrumentos que utilizam teorias e procedimentos, para adquirir a experiência, que confirmem a experiência;

4. Aprender os procedimentos e os caminhos para poder utilizá-los ao realizar outras experiências em outros contextos;

5. Aprender a usar o saber teórico aprendido para que esteja presente e seja utilizado quando se trata de realizar um processo completo de pesquisa. (SÉRÉ, 2002)

Faz-se necessário, pois, detectar a melhor abordagem dentro de cada situação ao aplicar as práticas experimentais. Dependendo da abordagem escolhida, as atividades práticas podem ter os seguintes objetivos, como afirma Borges (2002): servir para testar uma lei, ilustrar ideias e conceitos das aulas teóricas, além de deduzir uma fórmula ou lei acerca de um fenômeno. A recomendação é que se dividam os alunos em pequenos grupos, facilitando a interação no preparo do experimento e possibilitando a troca de ideias. Outra vantagem apontada é o caráter informal das práticas experimentais que contrasta com o formalismo e rigidez das aulas teóricas (BORGES, 2002).

Há também críticos das práticas experimentais no ensino, argumentando que são pouco efetivas para os estudantes, pois se gasta muito tempo em detalhes desimportantes no processo de ensino, tais como; montagem do experimento, coleta de dados, teste de equações e verificação de resultados previamente determinados. Nesse ponto de vista crítico das práticas experimentais, os estudantes não dedicam tempo suficiente à análise e interpretação dos resultados e que assim essas atividades terão pouca efetividade (COELHO et al, 2000).

Entre as principais dificuldades na introdução do ensino de ciências com laboratórios, Pinho-Alves (2000) apontam para o perigo de se ter vários objetivos não compatíveis 
em uma mesma atividade. Para ele e outros autores, deve-se procurar maneiras mais criativas e eficientes, com objetivos bem definidos, procurando usar metodologias que façam o ensino experimental e o ensino teórico concordarem, permitindo integrar prática e teoria e assim, tendo como resultado, o experimento servido de base à teoria.

Em um contexto mais geral, ao se descartar o uso dos laboratórios no ensino de ciências, o que acontece é que se reduz o ensino a um mero sistema abstrato de definições, fórmulas, leis e exercícios, sem conexão com o caráter fundamental das ciências que tem o experimento como principal agente de descoberta. As teorias da física têm sua construção em modelos matemáticos, porém, sem a comprovação experimental não seria possível obter a compreensão de como a natureza funciona e o porquê (AXT, 1991).

Para Pinho-Alves (2000), a experimentação no ensino precisa de um tipo de laboratório adequado para cada realidade e que esteja de acordo com os objetivos das instituições de ensino e professores. Os tipos de laboratórios devem ser estudados do ponto de vista de suas características.

Neste trabalho, optou-se pelo laboratório divergente, pois sua dinâmica concede ao estudante trabalhar sistemas físicos reais, permitindo a abordagem de problemas igualmente reais cujas respostas não são preconcebidas. Além disso, os alunos podem escolher qual o esquema e procedimento a serem adotados durante o estudo. $\mathrm{Na}$ etapa de exercícios, todos os alunos devem responder uma série de questões comuns a todos os estudantes, os procedimentos, medida, tudo visando o treino para a segunda etapa. Na segunda etapa, os alunos decidem qual atividade realizarão, seus objetivos e hipóteses a serem testadas, logo após a interação com o professor, pode haver a modificação e eventuais correções, assim como a verificação da viabilidade do material disponível e tempo par realização do experimento (BORGES, 2002). 


\section{FOGÃO FOGUETE}

Dentro da perspectiva de abordagem do laboratório divergente, fez-se a escolha de uma prática que envolvessem os fogões foguetes. Eles seguem os princípios de designe de Winiarski (1982) e do trabalho conjunto de Still e Winiarski (2001) que auxiliam na eficiência enérgica em comparação com outros fogões que utilizam biomassas como fontes de energia. Os tamanhos das aberturas do fogão são importantes, pois devem ser dimensionadas. Caso as aberturas sejam pequenas, a biomassa não poderá ser queimada apropriadamente e a fumaça poderá retornar ao local da combustão. Do mesmo modo, se as aberturas forem grandes, o calor não será transmitido para a panela escapando através da exaustão. Neste trabalho, utilizamos o modelo de fogão foguete tipo joelho, conforme o esquema da figura 1.

Figura 1: Esquema do fogão foguete tipo joelho. A base menor é composta por uma prateleira que serve como suporte para o combustível e uma entrada para o fluxo de ar. A parte maior e interna é a câmara de combustão onde o fluxo de ar se encontra com a chama. A parte de fora, neste exemplo, é de metal e, no topo, a saída para a chama e abertura para colocar a panela.

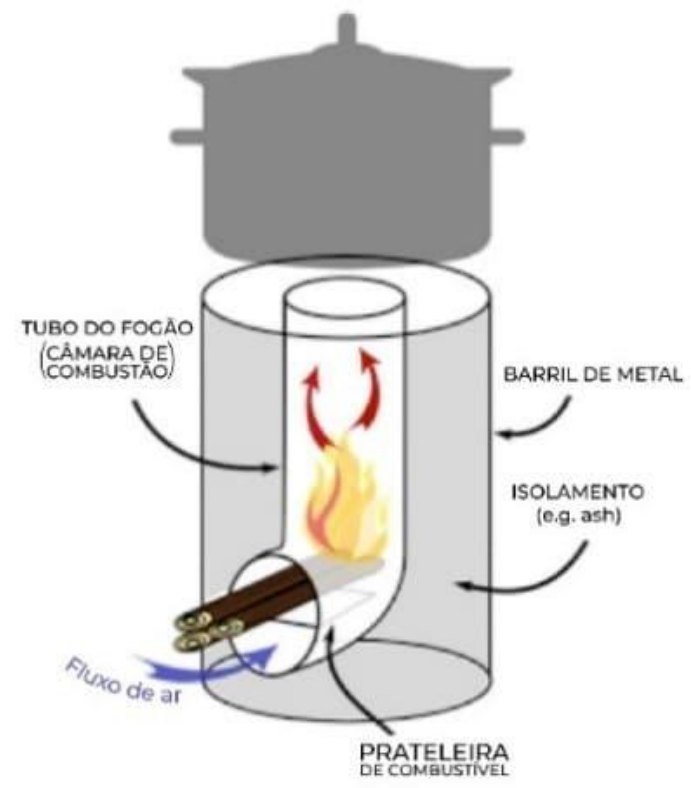

Fonte: imagem adaptada de Nokobunva (2016). 
O desflorestamento é um problema em muitos países do sul da Ásia. A substituição de fogões tradicionais de três bocas por fogões foguetes, reduziu em média o consumo de madeira de 3,68 toneladas para 2,706 toneladas por ano em cada casa. É grande a demanda por energia de pessoas vivendo em zonas rurais do Nepal dependentes de fontes de biomassas. Aproximadamente $64 \%$ da população do Nepal utiliza madeira como sua principal fonte de energia para cozinhar (SUBEDEE et al, 2017).

Em algumas regiões do mundo, devido ao desmatamento e outros fatores, o principal combustível utilizado para os fogões é o esterco seco. Porém, ele é menos energeticamente eficiente do que a madeira e o carvão (WITT et al, 2006). Como resultado do protótipo de fogão foguete que usa como combustível o esterco, em comparação com outros fogões que não seguem os princípios de Larry Winiarski (1982), o artigo apresenta que no teste da fervura da água, o protótipo é mais energeticamente eficiente e reduziu as emissões de $\mathrm{CO}$ em $44 \%$ comparado com o fogo diretamente na madeira. Mostrando que é um protótipo promissor ao baixar os níveis de poluição e reduzindo os prejuízos econômicos do uso de grandes quantidades de combustível.

Ochieng et al. (2013) e seus colaboradores, investigaram a emissão de monóxido de carbono (CO) em 102 residências para comparar as diferenças de emissão entre três tipos de fogões utilizados nessa região, sendo os tradicionais fogões de três pedras e fogão foguete de barro. Fazendo medidas contínuas durante $48 \mathrm{~h}$ nas cozinhas dessas residências, enquanto as concentrações da cozinha e pessoal de $\mathrm{CO}$ foram 7.3 e 6.5 ppm, respectivamente, para os fogões de três pedras, as concentrações correspondentes para os fogões foguetes foram 5,8 e 4,4 ppm. Levando-se em consideração a localização da cozinha, ventilação, status socioeconômico e concentração da mistura de combustível, o uso dos fogões foguetes de barro reduziram os níveis de $\mathrm{CO}$ associados à cozinha em $33 \%$ e os níveis pessoais em $42 \%$ comparado ao fogão de três pedras.

Os resultados deste estudo evidenciam que o uso de biomassas como combustível em cozinhas eleva os níveis de $\mathrm{CO}$ no interior das residências. Esse tipo de uso é 
bastante comum em domicílios rurais no oeste do Quênia. Embora a concentração de CO seja menor em domicílios que usam fogões foguetes, elas permanecem altas no geral, sugerindo que eles podem não produzir benefício significativo para a saúde respiratória. A redução substancial de concentrações de $\mathrm{CO}$ pode ter consequências para a saúde como resultado dos níveis de exposição de CO. Essas consequências precisam de uma investigação mais aprofundada.

Burnham-Slipper (2009) produziu um fogão foguete que apresentou bons resultados na otimização do uso de madeira, reduzindo a quantidade de combustível necessário para tarefas diárias, diminuindo a emissão de carbono e melhorando a qualidade de vida, principalmente de mulheres e crianças. No trabalho, utilizou um programa computacional de fluidodinâmica para otimizar as condições de combustível. De início, a fase experimental caracterizou a taxa de queima, temperatura de velocidade de queima do gás.

Winiarski (1982) apresenta princípios para otimizar os fogões que utilizam madeira como combustível. O fogão foguete utilizados aqui, se baseiam neles. São eles:

1. Isolar ao redor do fogo utilizando materiais leves e resistentes ao calor;

2. Coloque uma chaminé isolante acima do fogo para redirecionar a fumaça;

3. Aqueça as pontas das varas, gravetos e lenhas antes de colocálas ao fogo para que façam chamas e não fumaça;

4. Mais calor ou menos calor dependem de quantos gravetos são colocados no fogo;

5. Manter um bom graveto sob o fogo, através das brasas. Evite permitir muito ar extra acima do fogo para esfriá-lo;

6. Pouco graveto sendo puxado para o fogo resultará em fumaça e excesso de carvão;

7. Mantenha o fluxo de ar para o fogo, o espaço dentro do fogão, através do qual o ar quente flui e a chaminé deve ser da mesma espessura; 
8. Usar uma grade sobre o fogo;

9. Isolar o caminho do fluxo de calor do fogo ao redor da panela;

10. Maximize a transferência de calor para a panela com aberturas de tamanho adequado. (WINIARSKI, 1982)

Os fogões foguetes podem ser produzidos com os mais variados materiais de fácil acesso e baixo custo, tais como, latas de metal, barro, tijolos, madeira, etc. Gandigue e Nagarhalli (2018) apresentam uma revisão dos principais tipos de fogões foguetes e parâmetros que influenciam nas melhorias de eficiência em cada modelo.

Os parâmetros são relacionados ao tamanho da chaminé, câmara de combustível e aberturas de entrada de ar e saída do fogo. Se as aberturas forem muito pequenas, não poderá queimar apropriadamente o combustível e irá gerar fumaça. Por outro lado, se as aberturas forem excessivamente grandes, o calor escapa e não será utilizado com eficiência para aquecer a panela por exaustão. As dimensões dos parâmetros seguem os princípios de Winiarski (1982) e os parâmetros geométricos são encontrados pelas fórmulas de Dana (2009), que são:

$$
\begin{aligned}
& K=1,5 J \\
& H_{c}=K+J \\
& A=J x J \\
& L=\frac{1}{2} d+10
\end{aligned}
$$

As variáveis geométricas nas equações (01), (02), (03) e (04) são respectivamente: $K$ é a altura da chaminé até o final da câmara de combustão, $J$ sendo a altura da câmara de combustão, $H_{c}$ altura da chaminé da base do fogão, $L$ o comprimento da base onde se colocará o combustível e abertura para o fluxo de ar e $A$ é a área da câmara de combustão. 


\section{METODOLOGIA}

O presente trabalho foi desenvolvido nas aulas de práticas experimentais em um município da Paraíba. Os resultados apresentados aqui, constituem uma pesquisa qualitativa com intuito de apresentar uma abordagem experimental de tópicos de Física que dialoguem com outras disciplinas e se conecte ao contexto social dos alunos do sertão paraibano.

Inicialmente, os alunos foram expostos aos conteúdos de termologia, calorimetria e termodinâmica e aos princípios de funcionamento do designer do fogão foguete nas aulas teóricas de Física. Foram distribuídas 2 seções de aulas experimentais no primeiro bimestre letivo de 2020 , sendo que em cada seção era realizada 4 aulas experimentais. Os alunos se dividiram em 5 grupos e produziram o total de 5 fogões foguetes. A figura 2 exibe um dos fogões montados durante a aula. $\mathrm{O}$ material necessário para a produção dos fogões foi encontrado no próprio laboratório de ciências e os restos de resíduos sólidos (tijolos) encontrados no pátio da escola que estava passando por uma reforma.

A construção dos fogões ocorreu na área externa da escola onde os alunos ficaram livres para coletar o material necessário, seguindo assim os princípios de Winiarski e os parâmetros geométricos de Dana para otimizar o funcionamento do aparato. 
Figura 2: Fogão foguete construído com tijolos de restos da reforma da escola.

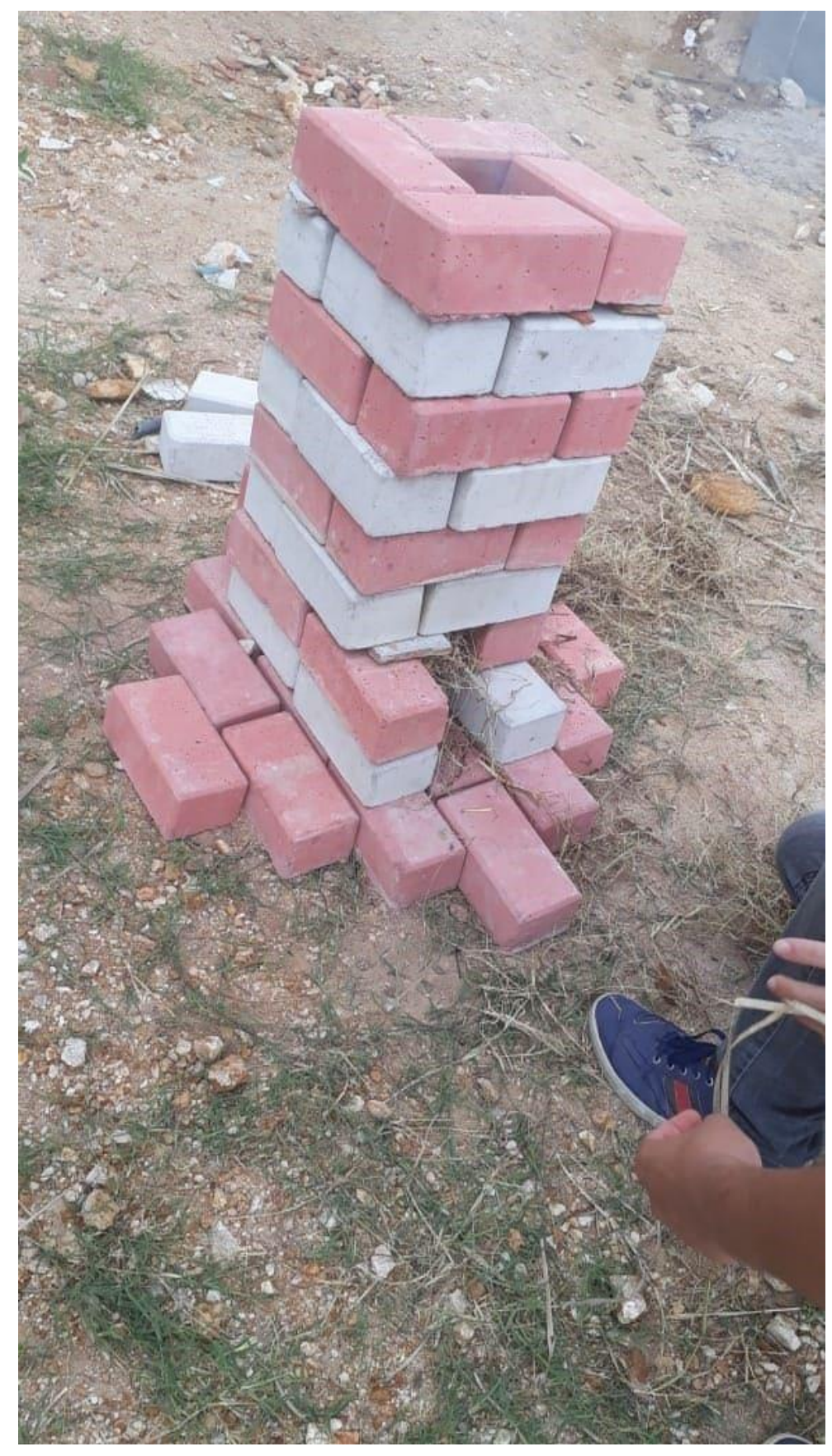

Fonte: autoria própria.

Após a realização do experimento, a fim de avaliar qualitativamente o aprendizado dos discentes, foi proposto um relatório com a seguinte estrutura obrigatória: introdução, materiais e métodos e conclusões. 


\section{RESULTADOS E DISCUSSÕES}

A construção do fogão foguete proporcionou um espaço de amplas discussões, as quais seriam difíceis serem abordadas com roteiros mais tradicionais de experimentos de física para o ensino médio. A metodologia levou ao tema das energias renováveis e não renováveis, discussões a respeito do efeito estufa causado, principalmente, por gases emitidos na queima de biomassas. Outra discussão levantada pelos próprios alunos foi a questão da eficiência que poderia ser alcançada usando parâmetros geométricos e conceitos da física.

Nos relatórios finais da prática, os alunos atribuíam grande importância das práticas experimentais nesse estilo em que as teorias ganham aplicações práticas e simples. Outra observação relevante dos discentes foi o fato de que a interação em grupo também facilitou a assimilação dos conceitos da física, pois dúvidas teóricas e eventuais problemas com a montagem do fogão experimental foram solucionadas de um modo em que se sentiam confiantes.

O experimento suscitou nos estudantes o caráter investigativo, levantando hipóteses sobre a lei da conservação da energia, transferência e propagação do calor. Quanto ao papel do docente nos trabalhos experimentais, é importante ressaltar o dever de ser um mediador, ofertando um roteiro de prática que seja simples e claro, isto é, retirando os passos demasiados complexos e por vezes desnecessários durante a montagem e execução do experimento. $O$ professor, ao propor trabalhos experimentais que envolvam mais de um conceito físico, como é o caso aqui, não deverá cair no erro de fornecer respostas fáceis aos questionamentos e dificuldades. Em seu roteiro e atuação, tem o cargo de promover as descobertas dos alunos, os quais, por intermédio da interação social e conhecimento prévio, encontrarão suas respostas.

A demonstração qualitativa da eficiência do fogão, em comparação com o tradicional fogão de três pedras, foi realizada pelos alunos de um modo prático e simples por comparação. Após a construção dos dois modelos de fogões (o de três pedras e fogão foguete), houve um debate reflexivo onde os grupos chegaram à conclusão que o 
melhor modo de testar a eficiência sem fazer cálculos, seria pesando, com auxílio de uma balança, quantidades iguais de madeira para os dois fogões. Desse modo, duas panelas iguais de alumínio, contendo quantidades iguais de água seriam postas simultaneamente nos dois fogões. Concluíram que o fogão que fizesse a água ferver primeiro e com menor quantidade de combustível queimado, seria o de melhor eficiência. Com o teste e afirmação positiva da hipótese comprovada, foi notório a empolgação dos alunos com o produto de seus esforços experimentais e teóricos.

\section{OUTRA PROPOSTA DE PRÁTICA EXPERIMENTAL PARA UMA ABORDAGEM QUANTITATIVA}

O fogão foguete também poderá ser utilizado em uma turma mais avançada de Física que já tenha conhecimentos sobre a teoria da transferência de calor e transferências de massas.

A técnica foi aplicada por Okonkwo et al (2017) para fazer o teste de eficiência de um protótipo desenvolvidos por eles. Para a análise, deve ser aplicado a lei da conservação da energia (RAJPUT, 2010):

$$
E_{\text {entrada }}-E_{\text {saida }}=\Delta \mathrm{E}
$$

Para o fogão foguete, a energia de entrada está relacionada à energia armazenada na madeira de acordo com a seguinte equação:

$$
E_{\text {entrada }}=M_{m} L_{m}-M_{c} H_{c}
$$

Onde $M_{m}$ é a massa da madeira, $L_{m}$ calor da madeira, $M_{c}$ a massa do carvão. A energia de saída é baseada na energia transferida para a água, que é modelada por:

$$
E_{\text {saida }}=M_{a} C_{p} \Delta T+M_{e} L
$$


Sendo $M_{a}$ a massa inicial da água, $C_{p}$ o calor específico da água, a variação de temperatura até a ebulição é $\Delta T, M e$ a massa da água evaporada e $L$ calor latente de vaporização da água. Nesse modelo, as perdas por condução são desprezadas, assim são consideradas por mudanças de energia para o fogão. Perdas por convecção e radiação podem ser calculadas para o fogão e panela baseados nas temperaturas das superfícies durante a combustão. A convecção é modelada pela lei de resfriamento de Newton:

$$
q=h A\left(T_{s}-T_{\infty}\right)
$$

Onde $q$ é a transferência de calor, coeficiente de transferência de calor $h$, área superficial $A$, temperatura da superfície $T_{s}$ e $T_{\infty}$ temperatura de radiação do ar no ambiente. É modelado pela lei de Stefan-Boltzmann:

$$
q=\varepsilon \sigma T_{s}^{4}-\alpha \sigma T_{\infty}^{4}
$$

Onde é o calor transferido, é a emissividade, é a constante de Stefan-Boltzamann, a é a absorvida de, $T_{\infty}{ }^{4}$ temperatura ambiente do fluido e $T_{s}^{4}$ temperatura da superfície. As transferências de energia são baseadas em termos das massas no fogão e panela. Os termos de energias armazenadas são baseados em calor específico do material de acordo com a seguinte equação:

$$
\Delta E=m C_{p} \Delta T
$$

Onde $m$ é a massa, $C_{p}$ calor específico e $\Delta T$ variação de temperatura. Portanto, as teorias fundamentais de transferência de calor, combinadas com a lei da conservação de energia determinam a magnitude e localização das perdas de calor do fogão. Usando a seguinte equação (TUKANA, 1993): 


$$
\begin{gathered}
E_{\text {entrada }}-E_{\text {saida }}=E_{\text {cond.dofogão }}+E_{\text {rad.dofogão }}+E_{\text {cond.dapanela }} \\
+E_{\text {rad.dapanela }}+\Delta E_{\text {fogão }}+\Delta E_{\text {panela }}+\Delta E_{\text {dif }} .
\end{gathered}
$$

E por fim, pode ser calculado a eficiência $\eta$ pela expressão da razão das energias de saída e entrada:

$$
\eta=\frac{E_{\text {saída }}}{E_{\text {entrada }}}
$$

Por essa proposta com foco mais quantitativo, o professor poderá utilizara o fogão foguete nas aulas experimentais para ensinar: a quantidade de calor, calor específico, calor latente, conservação da energia, primeira lei da termodinâmica, lei de StefanBoltzmann e outros tópicos de termodinâmica.

\section{CONSIDERAÇÕES FINAIS}

Propostas de práticas experimentais, ao serem incluídas no currículo, devem levar em consideração a realidade do ambiente escolar na qual está inserida. Assim sendo, o critério na escolha se faz necessário para envolver os alunos nas atividades. Os passos demasiados trabalhosos na montagem, medidas e cálculos das atividades precisam ser pensados para que não distraia o aluno do objetivo essencial.

O conhecimento científico da Física tem em si a dimensão, necessariamente, a compreensão teórica dos conceitos, mas também a comprovação mediante experimentos. Essas duas dimensões são complementares. Logo, a prática experimental se torna indissociável da teoria no processo de transposição didática.

A escolha do laboratório divergente possibilita um ambiente de liberdade criativa, interação de grupo, teste e refutação de hipóteses de um modo dinâmico e participativo. No entanto, o professor deve ter postura no sentido de apontar 
possibilidades sem dar respostas diretas e soluções às dificuldades dos alunos, pois nesse tipo de proposta, eles assumem uma posição de autonomia.

Em suma, a escolha de um experimento com materiais de baixo custo, propostas sustentáveis e montagem pelos próprios alunos, se torna vantajosa em escolas onde não há recursos de laboratório. A prática experimental do fogão foguete apresentou uma possibilidade multidisciplinar que vai além do simples ensino de tópicos de termodinâmica e comprovação experimental de assuntos vistos em aula teórica. Os alunos se sentiram conectados com um experimento que envolveu um problema comum do cotidiano para muito deles.

\section{AGRADECIMENTOS}

Agradeço fortemente à Fundação de Apoio à Pesquisa da Paraíba (FAPESQ-PB) pela bolsa de formação continuada de professor do edital n 009/2019 como quotas de bolsas do programa Gira Mundo Israel Semiárido, concedida pelo Governo do Estado da Paraíba.

\section{REFERÊNCIAS}

AXT, R. O papel da experimentação no ensino de ciências. Tópicos atuais em ensino de Ciências. Porto Alegre: Sagra, 1991.

BORGES, A.T. Novos rumos para o laboratório escolar de Ciências. Caderno Brasileiro .de Ensino de Física, v. 19, n. 3: p.291-313, 2002.

BURNHAM-SLIPPER, Hugh; CLIFFORD, Michael John; PICKERING, Stephen J. Breeding a Better Stove: the Use of Genetic Algorithms and Computational Fluid Dynamics to Improve Stove Design, 2009

CARVALHO, Ricardo Luis Teles de; SILVA, Adeildo Cabral da; LOMBARDO, Magda Adelaide. Saúde e risco ambiental: o caso dos usuários de fogão a lenha no estado do Ceará, região Nordeste do Brasil. Multidimensão e Territórios de Risco. Universidade de Coimbra, p. 513-517, 2014. 
COELHO, et al. Conceitos, atitudes de investigação e metodologia experimental como subsídio ao planejamento de objetos e estratégias de ensino. Caderno Brasileiro de Ensino de Física, v. 17, n. 12: p. 122-149, 2000.

DA SILVA, Edson Araujo. O Ensino de Física e as Energias Renováveis. Revista Acervo Educacional (online), v. 1, p. e1309-e1309, 2019.

Dana, B. Design Manual: Rocket box cook stove. Appropriate infrastructure development group. 2009.

DE ANDRADE, Jorge Augusto Nascimento; LOPES, Nataly Carvalho; DE CARVALHO, Washington Luiz Pacheco. Uma análise crítica do laboratório didático de física: a experimentação como uma ferramenta para a cultura científica. 2009.

FARIA, Filipe Pereira; CARNEIRO, Marcelo Carbone. O papel da experimentação na história do ensino de Física no Brasil. Debates em Educação, v. 12, n. 26, p. 36-51, 2020.

FORÇA, Ana Claudia; LABURÚ, Carlos Eduardo; DA SILVA, O. H. M. Atividades experimentais no ensino de física: teoria e práticas. VIII ENCONTRO NACIONAL DE PESQUISA EM EDUCAÇÃO EM CIÊNCIAS, v. 7, 2011.

GANDIGUDE, Aashish; NAGARHALLI, Madhva. Review of Rocket Cook-Stove Geometrical Aspects for its Performance Improvement. Materials Today: Proceedings, v. 5, n. 2, p. 4743-4747, 2018.

GOLDEMBERG, José; LUCON, Oswaldo. Energy and environment in Brazil. Estudos avançados, v. 21, n. 59, p. 7-20, 2007.

HODSON, Derek. Hacia un enfoque más crítico del trabajo de laboratorio. Enseñanza de las ciencias: revista de investigación y experiencias didácticas, p. 299-313, 1994. 
KANBACH, Bruno G.; LABURÚ, Carlos E.; SILVA, Osmar HM. Razões para a não utilização de atividades práticas por professores de física no ensino médio. Simpósio Nacional de Ensino de Física, v. 16, 2005.

MAIA, A.; GOMES, C. Possível uso da biomassa como alternativa para o fornecimento de energia do Brasil. Anais do XLI Simpósio Brasileiro de Pesquisa Operacional, v. 197, 2009.

MAZORRA, Javier et al. Panorama do uso de fogões melhorados no Semiárido brasileiro. Sustainability in Debate/Sustentabilidade em Debate, v. 10, n. 2, 2019.

NOKOBUNVA. Rocket Stove, 2016. Disponível em: https://en.wikipedia.org/wiki/File:Rocket_Stove.png . Acesso em 20 de maio de 2020.

OCHIENG, C. A.; VARDOULAKIS, S.; TONNE, C. Are rocket mud stoves associated with lower indoor carbon monoxide and personal exposure in rural Kenya?. Indoor Air, v. 23, n. 1, p. 14-24, 2013.

OKONKWO, Ugochukwu C. et al. Development of a rocket stove using woodash as insulator. Journal of Engineering and Applied Sciences, v. 10, n. 1, p. 1-13, 2017.

PEARCE, Joshua M. Teaching physics using appropriate technology projects. The Physics Teacher, v. 45, n. 3, p. 164-167, 2007.

PINHEIRO, T.F. Aproximação entre a ciência do aluno na sala de aula da $1^{\circ}$ série do $2^{\circ}$ grau e a ciência dos cientistas: uma discussão. Dissertação de Mestrado. CED/UFSC. Florianópolis, SC. 1996.

PINHO ALVES, J. Regras da transposição didática aplicadas ao laboratório didático. Caderno Catarinense de Ensino de Física, Florianópolis, v. 17, n. 2, p. 174188, ag. 2000.

PINHO ALVES, José. Atividade experimental: uma alternativa na concepção construtivista. VIII Encontro de Pesquisa em Ensino de Física, 2002. 
RAJPUT, R. K. A textbook of engineering thermodynamics. Firewall Media, 2010.

SANTOS, Pedro Vieira Souza. Elaboração de Projetos Práticos como Suporte ao Processos de Ensino-Aprendizagem de Física. Revista Científica Multidisciplinar Núcleo do Conhecimento. Edição 03. Ano 02, Vol. 01, p. 253-264, 2017.

SÉRÉ, M.G. La enseñanza em el laboratório? Qué podemos aprender em términos de conocimiento práctico y de actitudes hacia la ciência? Enseñaza de las Ciencias, v. 20, n. 3, p.357-368, 2002.

STILL, Dean; WINIARSKI, Larry. Increasing fuel efficiency and reducing harmful emissions in traditional cooking stoves. Boiling Point, v. 47, p. 36-39, 2001.

SUBEDEE, Bijay Raj et al. Use of Rocket stove for firewood savings and carbon emission reductions by the households involved in Allo (Girardinia diversifolia) fiber processing at Khar VDC, Darchula District, Nepal. International Journal of Latest Engineering and Management Research, v. 2, p. 28-35, 2017.

TUKANA, S.; LLOYD, C. R. Wood cookstoves in Fiji. Renewable energy, v. 3, n. 2-3, p. 165-172, 1993.

WINIARSKI, Larry. Ten Design Principles for Wood Burning Stoves. Retrieved May, v. 25, p. 2011, 1982.

WITT, Mark; WEYER, Kristina; MANNING, David. Designing a Clean-Burning, HighEfficiency, Dung-Burning Stove: Lessons in cooking with cow patties. Creswell Oregon: Aprovecho Research Center, 2006.

Enviado: Julho, 2020.

Aprovado: Julho, 2020. 